\title{
One at a Time: LGBTQ Polyamory and Relational Citizenship in the 2 Ist Century
}

Sociological Research Online 2019, Vol. 24(4) 709-725 (C) The Author(s) 2019

Article reuse guidelines: sagepub.com/journals-permissions DOI: $10.1|77 /| 3607804 \mid 9874080$ journals.sagepub.com/home/sro

@SAGE

\section{Ana Cristina Santos}

Centre for Social Studies, University of Coimbra, Portugal

\begin{abstract}
Drawing on biographic narrative interviews with self-identified lesbian, gay, bisexual, trans, and/or queer polyamorous people in Portugal, this article explores the contradictions and opportunities involved in living as a relationally diverse LGBTQ intimate citizen in Southern Europe. The article starts by unpacking citizenship in relation to dominant sociolegal expectations around monogamy. In this section, it is suggested that the mononormative underpinnings of law and social policy restrain intimate citizenship. The second part of the article explores the legal and cultural meanings attached to coupledom, suggesting the notion of relational performativity as an analytical tool for interpreting cultural norms and expectations around partnering. The last section discusses citizenship and coupledom in light of the biographic narratives produced by LGBTQ polyamorous participants in the INTIMATE study in Portugal. Based on thematic analysis of these narratives, it is argued that the framework of intimate citizenship is not fixed, and the notion of relational citizenship is offered. Arguably, relational citizenship enables a gradual detachment from the strictly monogamous underpinnings of citizenship studies, hence offering an opportunity for further intellectual engagement with intimacy and diversity in the 2 I st century.
\end{abstract}

\section{Keywords}

INTIMATE, LGBTQ polyamory, Portugal, relational citizenship, relational performativity, Southern Europe

\section{Introduction}

Polyamory can be defined as 'a form of relationship where it is possible, valid and worthwhile to maintain (usually long-term) intimate and sexual relationships with multiple partners simultaneously' (Haritaworn et al., 2006: 515), with the full knowledge and consent of

\section{Corresponding author:}

Ana Cristina Santos, Centre for Social Studies, University of Coimbra, Colégio S. Jerónimo, Apartado 3087, 3000-995 Coimbra, Portugal.

Email:cristina@ces.uc.pt 
everyone involved. This definition positions polyamory within the broader framework of relational diversity and, more specifically, consensual non-monogamies. With the exception of marriage laws and the legal ban of bigamy, in most geographical contexts consensual non-monogamy is not explicitly unlawful - it inhabits a pre-recognition space, it remains a-legal. Occupying the blurred territory of the a-legal border implies an additional layer of difficulty for those who claim broader inclusion and state recognition of relational diversity. In fact, this absence operates as a powerful symbolic device that strips relational diversity from public legitimacy and, to a large extent, visible existence. Furthermore, the a-legality of non-monogamy reinforces binary understandings and practices of intimate relations, suggesting there is, after all, 'one model, one pattern, one way' (Plummer, 2003: 14).

Two main consequences stem from the lack of legal acknowledgement of consensual non-monogamy. First, as Barker and Langdridge (2010) aptly note, non-monogamy continues to be 'demonized, pathologized, marginalized, and subject to the social regulation of ridicule [. . .] with no legal protections for people involved (for example around childcare or relationship status)' (p. 756). By failing to ascribe both legal and cultural recognition to non-monogamy, the Portuguese state betrays some of its most fundamental constitutional principles - namely the principle of equality (n. 13), the right to constitute family (n. 36), and the duty of the state in protecting every family (n. 67). Subsequently, this pushes relationally diverse people to uncomfortable situations in which multiple partners are 'sexual strangers' in the eyes of the lawmaker (Phelan, 2001) and poly parenting is not recognized under the eyes of the law-maker.

Second, the absence of formal recognition of consensual non-monogamy contributes to the narratives of intimate dissonance produced by LGBTQ intimate citizens for whom the polyamory closet is still very hard to break. Despite the consensual character of their relational experiences, narrative accounts display a tendency towards polyamory remaining a secret shared only with a handful of people, and certainly not with co-workers or employers. In this context, the lack of formal and cultural acknowledgement of consensual non-monogamy generates an asymmetry between the 'normal' intimate citizen, who the state is willing to acknowledge, and the dissident intimate citizen - the uncoupled, the non-parent, the non-cohabitant / solo living, the non-monogamous - who remains, at best, an outsider (Santos, 2013a).

Having these two premises as the contextual backdrop, this article starts by unpacking citizenship in relation to expectations around monogamy. In this section, it is suggested that the mononormative underpinnings of law and social policy restrain intimate citizenship. The second part of the article explores the legal and cultural meanings attached to coupledom, suggesting the notion of relational performativity as an analytical tool for interpreting cultural norms and expectations around partnering. In the last section, citizenship and coupledom are discussed in light of the biographic narratives produced by LGBTQ polyamorous participants in the INTIMATE study in Portugal. Polyamory will be considered in its specificities within the larger category of consensual non-monogamies. Drawing on thematic analysis of these narratives, it will be argued that the framework of citizenship is not fixed, and the notion of relational citizenship will be advanced. Arguably, relational citizenship enables a gradual detachment from the strictly monogamous underpinnings of citizenship studies, hence offering an opportunity for further engagement with intimacy and diversity in the 21 st century. 


\section{Citizenship and its mononormative script}

Citizenship is an overburdened notion, loaded with multiple, often conflictive, interpretations. For several decades, citizenship has been at the core of feminist and queer critical attention (Halsaa et al., 2012; Lister, 1997; Siim and Squires, 2008), which highlighted the mainstream, masculinist understandings of a notion that remained importantly defined by what it excludes. Post-structuralist contributions to citizenship theory namely Young's notion of group differentiated citizenship (Young, 1990) and Kymlica's notion of multicultural citizenship (Kymlica, 1995) - have advanced the understanding of citizenship as highly contingent, fragmented, and dynamic.

Faced with the dilemma of a concept that, on one hand, offers powerful tools in demanding state recognition and cultural visibility, and, on the other hand, carries a discriminatory symbolic legacy, feminist and queer theorists have suggested ways to push for a more inclusive notion - and practice - of citizenship. Stemming from such politicized awareness, scholars within gender and sexuality studies have advanced the notion of intimate citizenship, in use since the early 2000s:

Intimate citizenship looks at the decisions people have to make over the control (or not) over one's body, feelings, relationships; access (or not) to representations, relationships, public spaces, etc.; and socially grounded choices (or not) about identities, gender experiences, erotic experiences. It does not imply one model, one pattern, one way. (Plummer, 2003: 14)

What is called 'intimate' citizenship, using a terminology launched by policy feminists in Holland (Verloo and Roggebrand 1994) [ . . . ] focuses on bodily and sexual integrity and choice. Intimate citizenship ranges from power over fertility, including rights to contraception, decent health care and abortion, to issues about sexuality and gender itself, in terms of gay rights and the rights of transgendered people. (Woodward et al., 2011: 8)

Pushing the notion of citizenship to include intimate and sexual features was a crucial, but insufficient, step. In the aftermath of claims framed as intimate citizenship issues, collective action and decision makers tend to cluster rights according to a hierarchy of worth. The setting of a prioritizing agenda based on who is more worthy than others of more rights first seems to echo Michael Warner's (2000) earlier writings about shame, dignity and sexual politics. ${ }^{1}$ He contended that the LGBTQ movement was trying to 'clean' itself and that cleanliness in this sense is equivalent to desexualizing politics in order to transform it into something that 'you could take home to Mom' (Warner, 2000: 42).

Drawing on Warner's work, Diane Richardson (2004) argues that there is a shift in the cultural meanings attached to being lesbian or gay, which is 'increasingly constructed as a social rather than a sexual category' (p. 397). This shift translates itself into a normative focus on the 'desirability and necessity of marital-style sexual coupledom' (Richardson, 2004: 393). In other words, the 'normative emphasis is on the loving lesbian/gay couple living together in marital-style relationships, rather than the rights of the individual sexual actor' (Richardson, 2004: 397). These changes, Richardson (2018) suggests, contribute to the creation and recognition of the 'normal gay', who, according to Seidman, is '[e]xpected to be gender conventional, link sex to love and a marriage-like relationship, defend family values, personify economic individualism, and display national pride' (p. 
133). Seidman's 'normal gay' captures the sort of intimate citizen that the state is willing to embrace by publicly acknowledging relational encounters to the extent that they resemble existing (hetero)normative contracts. In fact, in Portugal as in other geographical contexts, one can say that LGBTQ family arrangements or sexual partnering have only been recognized under the law insofar as they accept being categorized as 'normal', as something that will unite - and not divide - society in accordance with shared traditions (Santos, 2013a).

In Southern Europe and beyond, law and social policy regarding partnering have been designed around the imaginary of the monogamous, cohabiting couple. As a result, especially in the aftermath of some level of formal relational recognition for same-sex couples, ${ }^{2}$ a significant part of what we could call the good intimate citizen profiling derives from mononormative expectations around partnering, regardless of sexual orientation. Dominant cultural expectations are also an important aspect of the way intimate citizenship becomes framed under the law. Romantic love endorses coupledom, and mainstream romantic love does not foresee the possibility of loving more than one person - at least not simultaneously. In so doing, current laws addressing partnering become trapped by cultural normative understandings of love, one of the most striking of which is mononormativity.

Mononormativity could be described as the normalness of monogamy (Pieper and Bauer, 2005; Robin, 2014). ${ }^{3}$ Also referred to in literature as compulsory monogamy and monocentrism, Barker and Langdridge (2010) speak of mononormativity in terms of 'certain rules and assumptions [that] are taken-for-granted including those of coupledom, privileging of love relationships over others, sexual exclusivity, and prohibition of relationships outside of the couple' (p. 4). Linked to this definition, it seems important to note that mononormativity can be extended to the sociocultural expectation that people feel attracted to only one gender, which will then impact on the disavowal - and related invisibility - of bisexuality (Gustavson, 2012; Monro, 2015). Institutional monogamy, in the resilient ways in which it permeates law and social policy, as well as education and popular culture, needs to be at the core of concerns about inclusive citizenship practices. Quoting Deri (2015), 'while monogamy is still the cultural norm, there is a vast array of relationship options which reside somewhere between monogamy and polyamory' ( $p$. 34). Finding the conditions to reach a full intimate citizenship comprehends an array of family and relational models, including polyamory.

Therefore, inspired by the challenges and opportunities posed by queering citizenship (Phelan, 2001) and affective transformations in families (Gabb, 2008), I argue for the need to detach citizenship from its current mononormative underpinnings. But before exploring ways of moving beyond compulsory monogamous understandings of citizenship, the next section invites a reflection on coupledom as a mainstream cultural performance that nourishes law and social policy regulating partnering in the Portuguese context.

\section{One at a time: doing coupledom in the eyes of the lawmaker}

This section examines legal and cultural meanings attached to coupledom, with a particular focus in the Portuguese context, in order to broaden understandings of partnering and relationality that move beyond monogamy. 
From a legal perspective, coupledom is sustained through the expectation of providing care and support based on sexual exclusivity between two cohabiting partners. Marriage - the legal institute which has historically regulated coupledom - is formally defined in Portugal as the 'contract between two people who intend to create a family through full communion of life' (art. n. 1577, Portuguese Civil Code). The Portuguese Civil Code identifies five marital duties: respect, fidelity, cohabitation, cooperation, and assistance (law decree n. 496/77, 25/11/1977). Three among these five marital duties are described in more detail. In short, spouses have to choose by common agreement a family residence, considering professional demands and children best interest, and they should cohabit at the family residence (article 1673); spouses are obliged to 'provide mutual assistance and aid, and to undertake family responsibilities together' (article 1674); and spouses must assist the family by providing food and contributing to expenses, even after separation if the court decides so (article 1675). Therefore, as such, marital duties both result from, and actively contribute to, the replication of a relational model which is embodied by the cohabiting, reproductive, monogamous, and (until 2010) heterosexual couple (Roseneil et al., 2012).

The tendency to somewhat crystalize the legal - and hence legitimate - 'couple' is in sharp contrast with an ever changing reality. Recent data show that divorce rates in Portugal are high and increasing, at the same time that remarriage has continued to grow (Torres et al., 2013). However, despite significant changes in recent decades regarding a gender-neutral marriage law (Santos, 2013b), the decriminalization of adultery (Hantrias and Letabiler, 2014) and the cultural acceptance of serial monogamy through divorce and remarriage (Guerreiro et al., 2009; Torres et al., 2013), the ability to openly engage in simultaneous relationships in any given moment in time remains unrecognized - at times even banned - under the law. Even at a time that has been described as 'plastic sexuality' (Giddens, 1992), in which it is increasingly rare to meet anyone who has only had one sexual or romantic partner throughout their life (Anapol, 2010), monogamy remains the by-default-position according to dominant cultural expectations. This cultural expectation is translated in law and social policy. The legal obligation to identify one single postal address for 'the' family home and to inhabit that address in order to 'protect the unity of family life' (article no. 1673) constitutes just one of many examples through which cultural expectations around monogamy operate through the legal framework in Portugal.

The centrality of monogamy in the Portuguese context can be interpreted in light of the historical legacy of the longest dictatorship in Southern Europe. Often described in literature as a Catholic country with a familistic welfare regime (Andreotti et al., 2001; Ferrera, 1996; Trifiletti, 1999), Portugal missed the years of free love and the sexual revolution experienced in other contexts, achieving (formally) some degree of sexual freedom much later. Homosexuality was decriminalized only in 1982 and the full access of lesbians and single women (regardless of sexual orientation) to medically assisted reproduction techniques is as recent as 2016. Nevertheless, the resilience of monogamy needs to be placed in a wider analytical framework that has impacts on Portugal and beyond.

Nathan Rambukkana's (2015) opening sentence in his book Fraught Intimacies: Non/ Monogamy in the Public Sphere sums it up well: 'monogamy is a strange animal' (p. 3). And the strangeness resides in both its resilience and the normalcy ascribed to a behaviour which 
is anything but standard, in the statistical sense at least. As Deri (2015) recently puts it, 'judging from the quantity of cultural narratives on adultery and the limited mainstream attention given to open relationships, adultery appears to be more socially acceptable than honest non-monogamy' (pp. 35-36). In other words, customary law and society are willing to accept multiple partnering across the life span, as long as they are reassured that the official relational focus at any given moment in time is a self-described monogamous relationship which will not overlap with any other intimate relationship that is presented publicly.

Two conclusions can be extracted. First, the doing of coupledom is highly performative, needs rituals, expects opponents, and relies on allies; this conjures up what I suggest to call relational performativity which is expected to be visibly monogamous. The notion of relational performativity describes the practices through which intimate relations are socially displayed; its point of departure is that intimate relationships are not sustainable in the void, but rather depend upon rehearsed scripts that guide interaction and become constitutive of the relational encounter. The performative character of intimate relationships draws on the Butlerian (1990) premise that gender is an act that requires both repetition and an audience in order to be recognized. Therefore, in the same way as heterosexuality is not sustainable without the public (i.e. visible) performative practices that ascribe meaning to an otherwise empty signifier, so do relationships require relational scripts and rituals through which they become socially recognizable, even when rejecting them. The concept of relational performativity is also strongly connected to dominant sociocultural expectations which, at any given geopolitical context, frame what an intimate relationship should or should not be (Ahmed, 2006; Roseneil et al., forthcoming). The glorification of a specific relational setting at the expense of a variety of others result in the further endorsement of oppressive regimes such as heteronormativity and mononormativity, with direct impact in the way intimacy is performed.

Second, in a time and space where most adults will have more than one partner throughout their lives, non-monogamy is only acceptable if it remains sequential (i.e. as a consequence of serial monogamy), but cannot be simultaneous. Couples can be multiple, as long as they are taken one at a time. This being the case, what seems to inspire legal guidelines regarding partnering is the time in which relationships occur, rather than the number of people involved or the conditions under which relational diversity operates across the individual life span. Therefore, full intimate citizenship understood as 'the freedom and ability to construct and live selfhood and a wide range of close relationships . . . safely, securely, and according to personal choice, with respect, recognition and support from the state and civil society' (Roseneil, 2010: 81-82) remains a political and theoretical aspiration, rather than an actuality. Both of these consequences will be further developed in the next section which offers an empirical account of relational diversity based on the INTIMATE qualitative study conducted in Portugal with self-identified LGBTQ polyamorous participants.

\section{Towards a relational citizenship - Portuguese polyamorists speak back}

To reiterate, in this article polyamory is used to describe consensual relationships in which it has been agreed between partners the possibility of maintaining intimate and/or sexual relationships with multiple partners simultaneously with the full knowledge and 
consent of everyone involved (Haritaworn et al., 2006). The notion of polyamory conjures up conceptual elaborations around relationships, relational practices, and the cultural imaginary around doing intimate relationships - aspects related to commitment, support, care, responsibility, attachment, and length (Klesse, 2011).

In the research project INTIMATE - Citizenship, Care and Choice: the micropolitics of intimacy in Southern Europe, we considered polyamory in its potential to offer new understandings of doing relationships and challenging the ways in which laws, social policies, and cultural practices are shaped by (hetero and mono)normative constraints of mainstream coupledom. By highlighting the multiple ways in which LGBTQ people engage in partnering, we hope to contribute to a timely and much needed debate on citizenship, care, and choice.

Arguably, the strategic use of polyamory can resemble the assimilationist use of the good intimate citizen on all grounds, except for - and importantly so - monogamy. Being aware of the political and theoretical implications of using the term polyamory (Haritaworn et al., 2006), it was decided to retain the use of this notion in the INTIMATE study based on the increasing mainstreaming of the word in the media and popular culture in Southern Europe and beyond (Cardoso et al., 2013; Deri, 2015; Mint, 2007).

But the most important reason for using polyamory within the INTIMATE research project was self-definition, that is, the need to acknowledge the participants' choice of self-identifying as polyamorous. In addition to social policy, academia, and activism, it is politically and conceptually important to consider narratives and experiences of LGBTQ people, how intimacy is constructed and managed on a daily basis, and the aspects in which practices around intimacy expose what is missing from literature, law, and social policy.

In the remaining part of this section, I want to suggest that we look at polyamory through a citizenship lens that stems from - but does not overlap with - intimate citizenship. This suggestion will be revisited through the accounts offered by participants in the INTIMATE study of polyamory in Portugal. Their accounts and embodied experiences give shape to the notion of relational citizenship which will be offered towards the end of this section.

The INTIMATE study on polyamory in Portugal was conducted in Lisbon in 2015, and it comprehended in-depth, biographic face-to-face interviews to anonymous participants, aged between 25 and 45 years old, and semi-structured interviews to experts from the fields of education, health, and politics, as well as fieldwork observation in events and virtual spaces, and the mapping out of relevant legislation and social policy in the Portuguese context. The empirical material that informs this article was analysed as part of a larger dataset composed of 42 interviews conducted in Portugal, Spain, and Italy. The sample of biographic interviewees in the polyamory study in Portugal is bisexual, mostly female and cisgender, and with no children. The biographic interviews conducted within the INTIMATE project have followed the Biographic Narrative Interpretive Method (BNIM) (Wengraf, 2007). This qualitative method enhances the researcher's ability to capture the complexities of real life experiences, as well as the discursive resources allocated to describe them, and how these shift over time, parallel to socio-political change. Our sample of narrative biographic interviewees excluded people who had not been at the forefront of politics or activism, who were leaders, or who acted as spokespersons. In so 
doing, we aimed at having access to both non-rehearsed narratives and also to people who are not usually heard when it comes to discuss citizenship, care, and choice. Recruitment strategies included flyers, digital calls for participants, and snowballing.

There are three main aspects in which polyamory lends itself to be discussed in light of citizenship. First, in multiple ways, the polyamorous has been inhabiting the limits of alegality and exposing the mononormative underpinnings of law and social policy, as argued in the first part of the article. The resilience of marital status as an unquestionable variable to fill in forms in procedures as diverse as registering a child in a new school or (until very recently) renewing your ID card testifies the importance of coupledom as a symbolic asset and a central feature of one's identity as an adult. ${ }^{4}$ More specifically, the lived experiences of polyamory occupy that grey zone of rejecting marital status while at the same time demanding relationship recognition; of offering a substantial critique of dominant coupledom while at the same time experiencing the daily management of conjugality; of detaching from romantic love while remaining attached to love by definition. In so doing, they represent the blurred edges, the fluidity through which individuals construct their intimate biography. As such, they offer an important contribution to rethink citizenship, care, and choice. One striking example is offered by Victoria, a transgender woman in her late 20 s, who embodies the continuum between friendship and love relationships:

There is not 'a day' which is the day in which the relationship begins. I've always considered my relationships as in . . I had male friends, I had female friends . . I mean, I was or I wasn't with that person, but no such thing as 'dating started here' or 'this is when we went steady', for me there is no turning point. [. . .] And I also believe we don't need to sexualize all the love relationships we've got. Our loves are constructions based on happiness. There are friendships which are love relationships. (Victoria, 25-29 years old, biographic interview)

For Victoria, personal relationships that matter escape the strict boundaries of linear development, are both sexual and asexual, do not comply with dominant dating timelines. In so doing, Victoria is challenging many assumptions about what makes a relationship into a significant intimate relationship in the eyes of the lawmaker.

Second, by seeking intimate commitment through an ethics of care and consent, polyamory challenges common ideas that having more than one significant other is damaging, selfish, or reckless. It seems significant to point out that, when the subject was legal aspects that should change, the two topics most commonly mentioned by participants were multi-partner parenthood and protection of partners in case of death or disease:

One of the priorities would be the issue of poli-parenthood, that [parenthood] could be multiple. Another priority would be that I could decide who gets to benefit from my possessions, a choice that would respect the way I lived my life. (Inês Rolo, activist from PolyPortugal at the time, Expert interview)

Still, this search for commitment is met with mainstream cultural disapproval stemming from a (mono)normative system which, in principle, holds commitment as an essential value, but insists in disregarding non-monogamous committed relationships. 
For instance, in our study it has been reported to be harder to come out of the poly closet than to come out as lesbian or gay to close family members. ${ }^{5}$

As such, polyamory is met with a contradiction constructed along the lines of committed practices and uncommitted representations. It is the ghost of uncommitted relationality that acts as a morally accepted excuse to disregard rights related to poli-parenting or relationship status, for instance. Susana, one of the participants in the study, said,

We don't have any type of representation, we're not visible at all and we don't have any rights. [. . .] If one of our children ends up in hospital, who gets to be there, who's got that right to be there? And even in situations of separation or death, right? It's difficult to understand what our rights consist of. [. . .] Possibly we'll have to swallow many bitter pills, or face many unfair situations in which we will not win, and that is sad. I mean we see it daily, it's always coupleoriented, a short-break for two and stuff. These tiny things are a pain, because we do not want it to be two of us, we want to be considered as the three of us. (Susana, 25-29 years old, biographic interview)

This contradiction also becomes visible in moments when people's relational status - sometimes together with sexual orientation, especially bisexuality - is dismissed or not taken very seriously. This was precisely what happened to Paulo, a bisexual man in his late 20s living in Lisbon, when he decided to come out to his mother who told him that everything was fine, that she accepted it, and therefore he could stop pretending he also liked women. This episode illustrates the ways in which bisexuality is rendered invisible, both in daily social interaction and in theoretical accounts (Erickson-Schroth and Mitchell, 2012; Klesse, 2007, 2010; Monro, 2015). Arguably, considering the absence of legal and cultural recognition that have been pointed out, bisexuality and polyamory might find common (relational) ground to acquire greater social and political recognition. Depreciation of relational status is also visible when Susana, a bisexual woman in her mid-20s, came out of the poly closet to her mother who was described as already expecting 'something completely crazy' from her daughter:

My mum was the first to realize that we were always together, the 3 of us, because she would come home from holidays and there would always be three things of each, in the dishwasher, always three, and she became suspicious, right? Three glasses, three plates, six, nine, and so on. She found it weird, and so I told her. She was already expecting something completely crazy from me, and so she was fine, she was already expecting me to come up with something [laughs]. (Susana, 25-29 years old, biographic interview)

And later on, in the same interview, Susana adds,

Once mum and I were chatting and she said something like "you two have adopted him as if he is your cat', or something. She thinks my relationships are a bit like, how should I put this, a product of a whim, for some reason that is how she sees my relationships, and it is precisely the opposite. (Susana, 25-29 years old, biographic interview)

Another example of dismissiveness, this time in the context of friendship, was offered by Vera, a bisexual woman in her 30s: 
When we're together with friends who are not aware [of their relationally diverse status], because these are people who have known each of us for such a long time, and many of those friends have an idea about our relationship which is like, oh, so cool, coz Vera she is not jealous, and Matias is not jealous, they have this relationship which is very open [. . .], and they just say nasty things and stuff. (Vera, 30-34 years old, biographic interview)

Finally, the third aspect in which polyamory engages with citizenship is through daily experience and practices of intimacy. Despite a relatively fragile asset of political and legal claims, through their daily practices of queer partnering polyamorous people are making a powerful contribution to rethinking citizenship, care, and choice (Klesse, 2011; Pallotta-Chiarolli, 2006). Polyamorous people contribute to this debate to the extent that, through practices of intimacy, they push the limits of what the state-endorsed legal framework of relationality recognizes. One of these limits is linearity:

That idea of Cinderella and Disney and the love story from the romantic comedy movies, and so on, that makes people believe that the most important thing in life is to find one partner. [. . .] And relationships are not just one thing, they are highly changeable over time. (Vera, 30-34 years old, biographic interview)

Narratives of shifting limits around acknowledged relations also include reflections about a new language of intimacy, with the idea of metamour (the partner of one's partner) emerging as an example:

We can have relationships which are not described anywhere else. For example, the relationship that we've got with the person who is dating the person we date. If we do not have a love relationship to that person, then we do have another type of relationship which is not described anywhere. It can be friendship, or not. (Inês Rolo, activist in PolyPortugal at the time, Expert interview)

There are also examples provided by participants in which they speak about polyamory as a journey stemming from the fact that one is constantly learning from experience, ongoing, changing, on the move, forthcoming. This aspect was central to Vera's narrative:

[poly to me] is a pathway for self-discovery, things that otherwise would be very difficult to reach [. . .], and is always worth it. To get to know more about yourself, even if it hurts, that's always worth it. And so, yah, it was a good choice, it was a good thing, it is a good thing. (Vera, 30-34 years old, biographic interview)

This feeling is described by Barker and Langdridge (2010) as follows: 'appreciation of the ever-shifting and changing nature of relationships, a commitment to flexible "boundaries" over rigid "borders" coupled with an understanding that just because one can go anywhere one does not have to go everywhere' (p. 762).

Therefore, despite refraining from advancing major collective claims, accounts of personal experiences of polyamorous participants are nevertheless highly political in their outcomes: 
In PolyPortugal I cannot think of anyone who is willing to struggle for a multipartner marriage act, a marriage for more than two, or than three. And that means something. [. . .] To make it more formal, never, especially because the dynamics of a poly relationship are always on the move and law attempts to crystalize things, to establish things, and poly is often anything but crystalized. (Inês Rolo, activist in PolyPortugal at the time, Expert interview)

In this regard, it is useful to refer back to Barker and Langdridge (2010) when they pose the crucial question 'of whether people need to be aware that they are doing something radical and challenging to the dominant ideology in order to be understood as participating in radical ways of living' (p. 755). As Deri (2015) points out, 'polyamory has transformative potential for systemic power inequalities' (p. 137).

Polyamorous intimate biographies offer new understandings of doing relationships against the backdrop of hetero/normative constraints of mainstream coupledom. As discussed, the lived experiences narrated by self-identified LGBTQ polyamorous people in Portugal expose significant gaps in sociological and citizenship literature. Therefore, shaped by significant developments regarding intimate, sexual, and reproductive citizenship, the complex arrangements in relation to care and choice in the context of polyamory push decision makers and theorists to change the ways in which citizenship is framed and enacted by law, social policy, and sociocultural outlets. Faced with that challenge, I want to advance the notion of (non-monogamous) relational citizenship to capture both the disjunctions and possibilities for reframing how we perceive, represent, and manage our intimate lives.

Highlighting the diversity in the way intimate biographies are constructed through partnering and friendship, the notion of relational citizenship describes the ways in which one self-perceives and is perceived by others as being partnered. These perceptions are informed by a hierarchy of value which differs depending on the degree of legal and/or sociocultural recognition achieved by any particular model of intimate relationship. Relational citizenship is two-pronged. On one hand, it engages the state by placing consensual non-monogamy at the core for demands of formal recognition and protection in the sphere of law and social policy. On the other hand, it focuses on informal recognition, addressing questions of identity and social validation, cultural norms and expectations, opportunities and obstacles that stem from the relational status of each individual. By engaging with both aspects of relational citizenship - the legal and the sociocultural - the emphasis is placed on the possibilities entailed or obstructed in present and future times regarding the right to individual's relational self-determination. It includes significant relationships; intimate, but not necessarily sexual or romantic. It can include cohabitation (or not), formally recognized coupledom (or not), monogamous, or more-than-one relationships. Relational citizenship shows the doing and undoing of coupledom and how that ever changing experience clashes with laws and social policy, exposing flaws and inconsistencies, and placing networks of friendship and care at the central core of queer relationality (Roseneil, 2004).

The notion of relational citizenship advanced in this article might be one step forward in the complex endeavour of detaching citizenship from its mononormative underpinnings. Furthermore, recognizing relational citizenship entails welcoming relational diversity as an asset, hence inscribing the legal and cultural recognition of multiple 
partners in the everydayness of human relationality. As such, relational citizenship also entails a queer reading of existing laws, pushing its boundaries by making use of ambiguous legal frames and creating case law. Importantly, advancing the notion of relational citizenship does not imply constructing the state and the legal pathway as the only source of valid kinship - or, as Butler (2004) aptly puts it, "desiring the state's desire." Conversely, it simply underlines the right to expect that both the state and the sociocultural context recognize diversity and relational self-determination by accommodating the different institutional settings - including health care, education, and family law - to an array of consensual relational models.

One possible approach to polyamory under existing legal codes in Portugal is offered by the shared economy law, which came into force in 2001 (Law 6/2001, 11 May) to protect people who cohabit. This law applies to people (two or more people, one of them must have the minimum age of 18 years old) who share a household for more than 2 years, sharing assistance and resources. Under this regime, contrary to de facto unions (approved in Parliament in 2001) and marriage (approved in Parliament in 2010), sharing bed is not a required feature. It was precisely due to the focus on economy instead of intimacy that the lesbian, gay, bisexual, and transgender (LGBT) community rejected this as a possibility for legal recognition of same-sex relationships; as a result, in 2001 both laws were approved in Parliament regardless of sexual orientation - de facto unions and shared economy (Santos, 2013b).

People living in shared economy have the right to (article 4):

Benefit of the legal vacation regime, absences, and leaves, and preference in the placement of staff of the Public Administration equated to the spouses' rights;

Benefit of the legal regime of vacations, holidays, and absences, equated to the spouses' rights;

Application of the personal income tax under the same conditions of married taxpayers not legally separated of persons and property;

Protection of common dwelling house;

Transfer of the rent contract in case of death.

It is important to note, however, that even in this apparently progressive piece of legislation there are couple-oriented clauses. In case of shared economy by more than two people, only one person has the right to (a) and (b), instead of having these rights granted to all members. Nevertheless, the shared economy law offers a good ground for enacting relational citizenship in already existing laws and social policies. ${ }^{6}$

\section{Conclusion}

A piece published in The Guardian in 2016 started as follows:

Low incomes, coupled with rising living costs, debt and a lack of employment mean that some of us are not only unlikely to fulfil our more inventive childhood fantasies, but will fail to meet 
even the basic milestones of adulthood: a full-time permanent job, a life partner, a home, a pension and earning enough every month to put something into a savings account. Here Guardian readers share their experiences of missing milestones. (The Guardian, 10/03/2016, 'Five markers of adulthood millennials have had to give up on')

In one single paragraph, several layers of what we strongly take issue with at the INTIMATE research are exposed. One of these layers is mononormativity, coupled (pun intended) with compulsory partnering. Why would we think of not having a 'life partner' as failure if it was not for the invisible, unquestionable, supreme mononormative script? Interviewed for the INTIMATE project in 2015, Gabriela Moita, sexologist and former President of the Portuguese Society of Clinical Sexology between 2013 and 2015, made an important remark:

This idea that you can only truly love one person, and that the rest is love through failure - this is the idea with which we grow up since birth, the idea that there is only one true love. And we must overturn this, we must destroy this idea by making people think, making people see the difference, and to experience the difference. [. . . ] In the old days, lesbians were considered sick, and before that they were sinners or criminals, and this is all stemming from the way love is conceptually constructed.

For the purposes of this article, the analytical focus was on relational citizenship, as both notion and practice, theory and politics, aspiration and experience. Today it is argued that citizenship can be understood both as 'an academic and political concept and as lived experience' (Lister et al., 2007: 1). In such context, it seems important to consider the mutual implications of intimacy and citizenship, exploring the extent to which issues of partnering, parenting, and friendship are important aspects of being/ becoming recognized as citizens. Given this challenge, the intention is to move beyond any theoretical dispute between intimate and sexual citizenship (Plummer, 2003; Richardson, 2018), in order to advance reciprocal ways in which these and other perspectives on citizenship can - and should - contribute to the politics and practices of intimacy in everyday life. The notion of relational citizenship, based on the intimate biographies of everyday LGBTQ polyamorous people, may be an important step towards reframing care, choice, and learning from the uniqueness of each individual story.

Participants' accounts add vivid empirical layers to the ambition of stripping laws and social policy of its by-default-monogamous assumptions, without formulating a sharp attack on monogamy as a relational orientation. In fact, data we collected is in agreement with Deri (2015) when she contends that 'Most polyamorists do not advocate the abolition of monogamy. Rather, they critique institutional monogamy with the goal of lessening the cultural dominance of mono-normativity' (pp. 37-38).

The accounts we gathered also acknowledge the centrality of academia in adding visibility and legitimacy to non-monogamous partnering practices. This should encourage scholars and other knowledge produces to move beyond existing frameworks and notions. One example would be situated at the level of the analytical focus: monogamy needs to be scrutinized (Emens, 2004), placed under the questioning light. If we are to speak of consensual non-monogamies, we should consider using the same adjective when referring to monogamy (consensual monogamy). Otherwise we are simply reinforcing the dominant 
by-default position of monogamy as 'normal', unquestionable, and therefore lacking the need for being negotiated among partners, lacking the need for ground rules or recognition regarding its construed (as opposed to 'natural') character. Another example of how academia can contribute to counter mononormativity is through the development of more adequate conceptual tools. As an attempt to meet such a call, in this article the terms relationally diverse people and relationally diverse coupledom were advanced as ways to overcome a notion which is mostly defined by what it is not - non-monogamous - without getting constricted by the compulsory use of polyamory when trying to overcome the prefix 'non'. Other options could include poly-partnering in alternative to polyamory. In this article, the notion of relational performativity was also advanced as a way to frame the public enactment of coupledom according to a set of rules, roles, and expectations, reinforced through rituals and allies, who rely predominantly on a monogamous script.

Finally, the key issue here concerns a rejection of the legal and cultural hierarchy between consensual relational orientations and practices. Relationships which are beyond the law have historically remained vulnerable, subject to violence, lacking both definition and protection (Santos, 2016). The absence of any form of public recognition of multiple partners in formal legal codes constitutes therefore a failure of the state in accommodating a diversity of intimate relational models. Moreover, it represents the contradiction through which one can claim legitimate recognition based on divorce, remarriage, or civil partnership, but cannot do so when engaged in multiple, simultaneous intimate relationships. The failure of the state in acknowledging relationally diverse people pushes non-monogamy to a limbo with necessary consequences which I tried to demonstrate through the study conducted with self-identified LGBTQ polyamorous people in Portugal.

Arguably, polyamory offers the opportunity to rethink citizenship, an intersectional relational citizen always in the process of becoming, actively seeking to achieve recognition while at the same time holding on to the freedom of constructing themselves as they go along, challenging the mononormative script of partnering, one at a time. A stranger, in a territory of prescribed coupledom. Hopefully relational citizenship will contribute to the undoing of the monogamous script of citizenship, hence encouraging further engagement with intimacy and diversity in the 21 st century.

\section{Funding}

The author(s) disclosed receipt of the following financial support for the research, authorship, and/ or publication of this article: The research leading to these results has received funding from the European Research Council under the European Union's Seventh Framework Programme (FP/2007-2013) / ERC Grant Agreement 'INTIMATE-Citizenship, Care and Choice: The Micropolitics of Intimacy in Southern Europe' (338452).

\section{Notes}

1. This argument can also be illustrated by sociocultural constraints elderly people face regarding sexuality (King et al., 2018, 2019; Simpson et al., 2018).

2. In Portugal, de facto union and marriage, since 2001 and 2010 respectively; in Spain, marriage, since 2005; in Italy, civil partnership, since 2016 (despite this recognition being far from being fair or inclusive, as Italian queer activists have rightly pointed out in the media; see, for 
instance, http://www.thelocal.it/20160225/anger-as-italy-cooks-gay-civil-unions-bill-making -children-second-class-citizens).

3. The term was coined by Pieper and Bauer (2005), Polyamory und Mono-Normativität: Ergebnisse einer empirischen Studie über nicht-monogame Lebensformen. It was cited in Barker and Langdrigde (2010: 750).

4. The centrality of coupledom as a marker of adulthood is a key argument of the work developed by Roseneil et al. (2012, forthcoming). Such centrality of coupledom is also supported by studies conducted within INTIMATE.

5. These findings are in accordance with the argument made by Gusmano regarding bisexuality (Gusmano, 2018).

6. Other relevant pieces of legislation that could be interpreted as (potentially) relationally inclusive include step-parenting and the Decree-Law n. 70/2010 regulating the conditions to consider when attributing benefits based on solidarity and social support. This document defines household as the group of people who lives in shared economy, and shared economy is defined as the group of people "who live sharing table and house, and who have established a common experience of mutual aid and sharing of resources' (line 2, article 4). In addition there is the governmental programme Social Rental Housing that provides houses to disadvantaged families, at a lower price than its respective market value. In the application form for social rental housing, shared economy appears alongside other categories as an option for 'marital status'. This means that, although preference is ascribed to coupledom or to the family over singledom, the programme adopts a notion of household that includes shared economy, in line with the notion of household defined by Decree-Law n. 70/2010. Finally, married, in de facto union, or people living in shared economy have the right to take 15 days off to provide immediate and necessary assistance to a partner in case of illness or accident (article 252, Labour Code).

\section{References}

Ahmed S (2006) Queer Phenomenology. Orientations, Objects, Others. Durham, NC: Duke University Press.

Anapol D (2010) Polyamory in the 21st Century: Love and Intimacy with Multiple Partners. New York: Rowman \& Littlefield.

Andreotti A, Garcia SM, Gomez A, et al. (2001) Does a Southern European model exist? Journal of European Area Studies 9(1): 43-62.

Barker M and Langdridge D (2010) Whatever happened to non-monogamies? Critical reflections on recent research and theory. Sexualities 13(6): 748-772.

Butler J (1990) Performative acts and gender constitution: An essay in phenomenology and feminist theory. In: Case S-E (ed.) Performing Feminisms: Feminist Critical Theory and Theatre. Baltimore, MD: Johns Hopkins University Press, pp. 519-531.

Butler J (2004) Is kinship always already heterosexual? In: Butler J (ed.) Undoing Gender. New York: Routledge, pp. 102-130.

Cardoso D, Martins IR and Coelho S (2013) Debating polyamory as research: An auto-ethnographic account of a round-table on polyamory and lesbianism. LES Online 5(1): 20-34.

Deri J (2015) Love's Refraction: Jealousy and Compersion in Queer Women's Polyamorous Relationships. Toronto, ON, Canada: University of Toronto Press.

Emens E (2004) Monogamy's law: Compulsory monogamy and polyamorous existence. Public Law Working Paper no. 58. Chicago, IL: University of Chicago.

Erickson-Schroth L and Mitchell J (2012) Queering queer theory, or why bisexuality matters. In: Alexander J and Anderlini-D'Onofrio S (eds) Bisexuality and Queer Theory. London: Routledge, pp. 105-123. 
Ferrera M (1996) The 'southern model' of welfare in social Europe. Journal of European Social Policy 6(1): 17-37.

Gabb J (2008) Researching Intimacy in Families. Basingstoke and New York: Palgrave Macmillan. Giddens A (1992) The Transformation of Intimacy: Sexuality, Love and Eroticism in Modern Societies. Cambridge: Polity Press.

Guerreiro MD, Torres A and Lobo C (2009) Changing families: Configurations, values and recomposition processes. In: Guerreiro M, Torres A and Capucha L (eds) Welfare and Everyday Life (Portugal in the European Context, Vol. III), CIES, ISCTE-IUL. Lisbon: Celta Editora, pp. 7-35.

Gusmano B (2018) Coming out in an intersectional perspective: Narratives of bisexuality and polyamory in Italy. Journal of Bisexuality 18(1): 15-34.

Gustavson M (2012) Bisexuals in relationships: Uncoupling intimacy from gender ontology. In: Alexander J and Anderlini-D'Onofrio S (eds) Bisexuality and Queer Theory: Intersections, Connections and Challenges. New York: Routledge, pp. 215-238.

Halsaa B, Roseneil S and Sumer S (eds) (2012) Remaking Citizenship in Multicultural Europe: Women's Movements, Gender and Diversity. Basingstoke; New York: Palgrave Macmillan.

Hantrias L and Letabiler MT (2014) Families and Family Policies in Europe. New York: Routledge. Haritaworn J, Lin CJ and Klesse C (2006) Poly/logue: A critical introduction to polyamory. Sexualities 9(5): 515-529.

King A, Almack K and Jones RL (2019) Intersections of Ageing, Gender and Sexualities: Multidisciplinary International Perspectives. Bristol: Policy Press.

King A, Almack K and Suen Y-T (2018) Older Lesbian, Gay, Bisexual and Trans People: Minding the Knowledge Gaps. New York: Routledge.

Klesse C (2007) The Spectre of Promiscuity: Gay Male and Bisexual Non-monogamies and Polyamories. Aldershot: Ashgate.

Klesse C (2010) Paradoxes in gender relations: [Post] feminism and bisexual polyamory. In: Barker M and Langridge D (eds) Understanding Non-Monogamies. New York: Routledge, pp. 109-120.

Klesse C (2011) Notions of love in polyamory - Elements in a discourse on multiple loving. Laboratorium 3(2): 4-25.

Lister R (1997) Citizenship: Feminist Perspectives. Basingstoke and New York: Palgrave Macmillan.

Lister R, Williams F, Anttonen A, et al. (2007) Gendering Citizenship in Western Europe: New Challenges for Citizenship Research in a Cross-national Context. Bristol: Policy Press.

Mint P (2007) The strange credibility of polyamory. Available at: https://freaksexual.wordpress. com/2007/11/27/the-strange-credibility-of-polyamory/ (accessed 14 March 2016).

Monro S (2015) Bisexuality: Identities, Politics, and Theories (Genders and Sexualities in the Social Sciences). London: Palgrave Macmillan.

Pallotta-Chiarolli M (2006) Polyparents having children, raising children, schooling children. Lesbian and Gay Psychology Review (International) 7(1): 48-53.

Phelan S (2001) Sexual Strangers: Gays, Lesbians, and Dilemmas of Citizenship. Philadelphia, PA: Temple University Press.

Pieper M and Bauer R (2005) Polyamory und Mono-Normativität. Ergebnisse einer empirischen Studie über nicht-monogame Lebensformen. In: Méritt, Laura; Bührmann, Traude; Schefzig, Najda Boris (Hg.): Mehr als eine Liebe - Polyamouröse Beziehungen. Berlin (Orlanda), S. 59-69.

Plummer K (2003) Intimate Citizenship: Private Discussions and Public Dialogues. Seattle and London: University of Washington Press.

Rambukkana N (2015) Fraught Intimacies: Non/Monogamy in the Public Sphere. Toronto, ON, Canada: UBC Press.

Richardson D (2004) Locating sexualities: From here to normality. Sexualities 7(4): 391-411. 
Richardson D (2018) Sexuality and Citizenship. Cambridge: Polity Press.

Robin M (2014) Queer BDSM Intimacies: Critical Consent and Pushing Boundaries. Basingstoke and New York: Palgrave Macmillan.

Roseneil S, Crowhurst I, Hellesund T, et al. (2012) Intimate citizenship and the tenacity of the couple norm: A cross-national analysis. In: Paper presented during the politics of location revisited: Gender@2012,8th European feminist research conference, 17-20 May, Budapest.

Roseneil S, Crowhurst I, Hellesund T, et al. (forthcoming) The Tenacity of the Couple Norm. Palgrave Macmillan.

Roseneil S (2004) Why we should care about friends: An argument for queering the care imaginary in social policy. Social Policy and Society 3(4): 409-419.

Roseneil S (2010) Intimate citizenship: A pragmatic, yet radical, proposal for a politics of personal life. European Journal of Women's Studies 17(1): 77-82.

Santos AC (2013a) Are we there yet? Queer sexual encounters, legal recognition and homonormativity. Journal of Gender Studies 22(1): 54-64.

Santos AC (2013b) Social Movements and Sexual Citizenship in Southern Europe. Basingstoke: Palgrave Macmillan.

Santos AC (2016) 'In the old days, there were no gays': Democracy, social change and media representation of sexual diversity. International Journal of Iberian Studies 29(2): 157-172.

Siim B and Squires J (eds) (2008) Contesting Citizenship. London: Routledge.

Simpson P, Wilson C, Brown L, et al. (2018) 'We've had our sex life way back': Older care home residents, sexuality and intimacy. Ageing and Society 38(7): 1478-1501.

Torres A, Coelho B and Cabrita M (2013) Bridge over troubled waters: Family, gender and welfare in Portugal in the European context. European Societies 15(4): 535-556.

Trifiletti R (1999) Southern European Welfare Regimes and the worsening position of women. Journal of European Social Policy 9(1): 49-64.

Warner M (2000) The Trouble with Normal: Sex, Politics and the Ethics of Queer Life. Cambridge, MA: Harvard University Press.

Wengraf T (2007) Guide to BNIM biographic-narrative interpretive method: Interviewing for life histories, lived situations and ongoing personal experiencing.

Woodward AE, Bonvin JM and Renom M (eds) (2011) Transforming Gendered Well-Being in Europe: The Impact of Social Movements. Farnham: Ashgate.

\section{Author biography}

Ana Cristina Santos With a background in Sociology and a PhD in Gender Studies, University of Leeds, UK, Ana Cristina Santos is a Senior Researcher at the Centre for Social Studies, University of Coimbra. Over the years she has coordinated a number of research projects on LGBTQI+, gender, dissident bodies, intimate citizenship and human rights, including the ERC cross-national study INTIMATE - Citizenship, Care and Choice (2014-2019) and the Portuguese Research Team of the International Consortium CILIA LGBTQI+ Lives, funded by the European Agency NORFACE (2018-2021).

Date submitted 19 April 2018

Date accepted 14 August 2019 